\title{
The workshop on "Biophysics and Structural Biology at Synchrotrons" presented at the University of Cape Town from 16-24 January 2019
}

\author{
Bryan Trevor Sewell ${ }^{1}$
}

Received: 30 June 2019 / Accepted: 30 June 2019 / Published online: 15 July 2019

(C) International Union for Pure and Applied Biophysics (IUPAB) and Springer-Verlag GmbH Germany, part of Springer Nature 2019

The most common response to the question "Why are you studying Biochemistry/Biophysics?" from South African post-graduate students is almost certain to be coupled to a desire to contribute to finding a cure for a disease. The study of infectious diseases dominates the South African Biochemistry landscape. The students and their mentors know about the power of structural and biophysical techniques to help understand the detailed mechanism of infection and to suggest the design of potential drugs, but very few have firsthand experience in accessing the technology that makes it possible to identify, purify, and visualize potential drug targets. The problem is that no country in Africa has prioritized spending in a way that would make drug discovery a practical reality and thus the tools used for target visualization, including synchrotrons or even modern cryo-electron microscopes are not available in Africa.

Some fifteen years ago scientists began to lobby for such resources - their efforts resulted in drawing up a roadmap (http://www.synchrotron.org.za/wiki/Main/HomePage) that will culminate in the construction of the African Light Source (AfLS). A key component of the roadmap is the expansion of the local user community by preparing and enabling scientists to use resources abroad. This involves not only training to use synchrotron beamlines but also assistance in designing projects, preparing material, and using complementary resources located both at home and abroad. Without significant funding, progress in implementing the roadmap would remain an idle dream. A significant input towards funding this dream came from the

This article is part of a Special Issue on 'Biophysics \& Structural Biology at Synchrotrons' edited by Trevor Sewell.

Bryan Trevor Sewell

trevor.sewell@uct.ac.za

1 Structural Biology Research Unit, Department of Integrative Biomedical Sciences, Institute for Infectious Diseases and Molecular Medicine, University of Cape Town, Cape Town, South Africa
Global Challenge Research Fund of the UK Science and Technology Facilities council in a grant awarded to Prof. Chris Nicklin at Diamond Light Source in UK. The program called START (Synchrotron Techniques for African Research and Technology) contributed $£ 1.3$ million to the practical training of a corps of African researchers in this area through the funding of posts for post-doctoral research associates, travel to and from the Diamond Light Source, the creation of a resource center in Cape Town, and the holding of annual workshops. The workshop "Biophysics and Structural Biology at Synchrotrons" held in Cape Town from the 16-24 January 2019 was a significant milestone on the roadmap. Support from the International Union of Pure and Applied Biophysics enabled students and young scientists from the entire country to participate.

The workshop was presented by researchers from the UK (Gwyndaf Evans, David Hall, Neil Paterson, Nicholas Devenish, Frank von Delft, Ophir Gileadi, Raymond Owens, Elspeth Garman, and David Bhella), Spain (Eva Pereiro), Italy (Silvia Onesti), Brazil (Richard Garratt), Australia (Michael Lawrence and Frances Separovic), India (Subramaniam Ramaswamy), and South Africa (Paul Kappo, Wolf-Dieter Schubert, Jeremy Woodward, Andani Mulelu, and Trevor Sewell). The scope of the workshop included protein sample preparation, crystallization, data collection, data processing and interpretation, and apart from X-ray crystallography, included other structural techniques, including cryo-electron microscopy, X-ray microscopy, and NMR spectroscopy. Several case studies were presented and gave students an understanding of how science happened in the "real world" and there was ample opportunity to share experiences of the development of science at and around synchrotrons from the perspective of users from countries having widely varying economies.

Students, who were sponsored by IUPAB, came from the Universities of Cape Town, Stellenbosch, Pretoria, Kwa-Zulu Natal, Zululand, Venda, Free State, Witwatersrand, Rhodes, Unicamp (Brazil), and the National Institute of Communicable Diseases (Fig. 1). Of the 49 students who registered, 33 were 


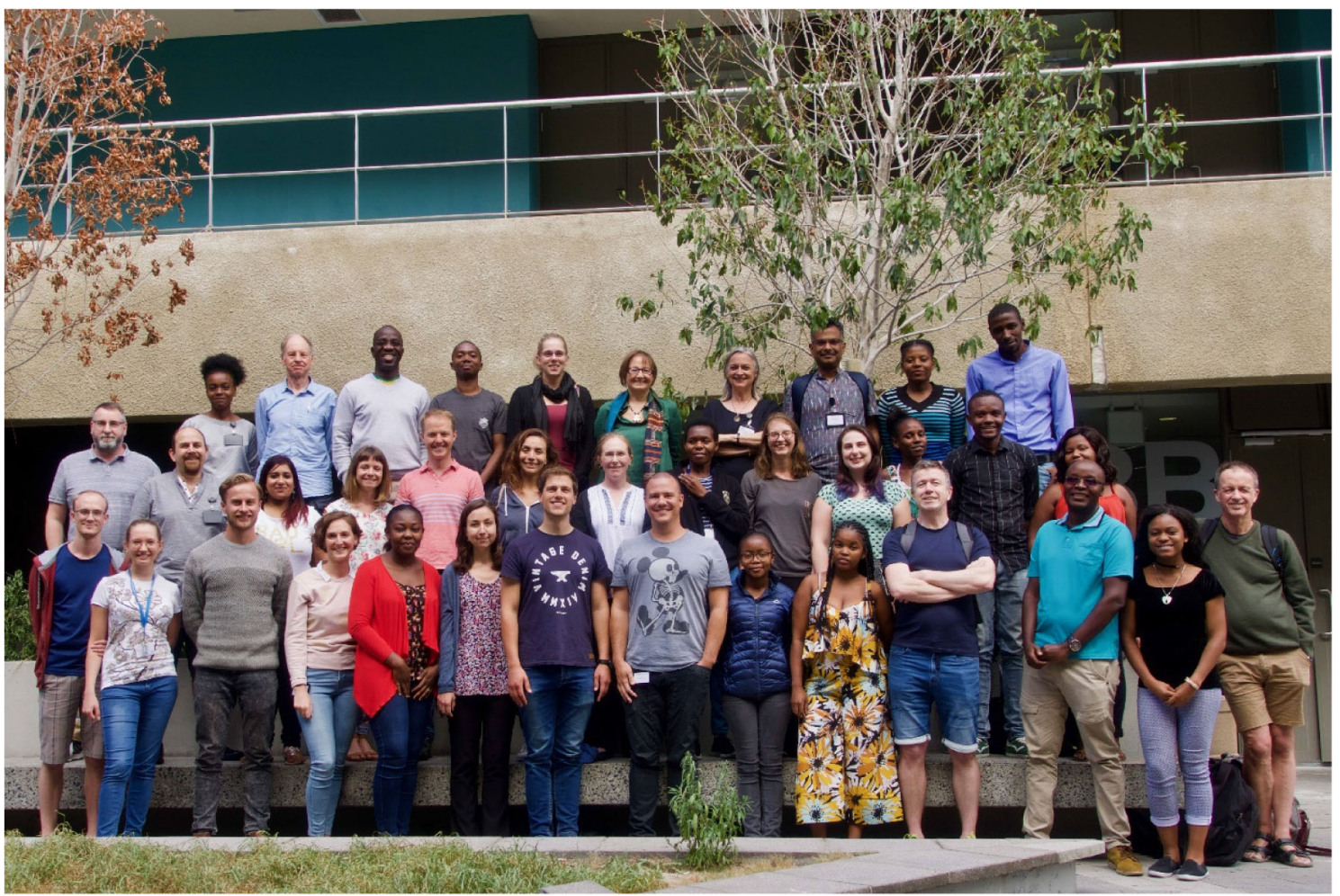

Fig. 1 Group photograph of the lecturers and students at the meeting

female representing a positive forward view for the participation of women in the fields of Biophysics and Structural Biology.

None of the 50 synchrotrons currently in operation worldwide are in Africa. This fact alone presents a considerable barrier to African scientists seeking to work on problems in which it is necessary to know the structure of proteins. The context of START is to lower that barrier both by providing advice on how to gain access to the resources at Diamond and by showing the early career scientists how to make best use of them. The discipline of Structural Biology has been neglected in Africa with the consequence that successful techniques for understanding, developing, and designing drugs, vaccines, and agrochemicals are neither taught nor applied on the continent, and therefore Africans have a dependency on products developed in the first world. START aims at correcting this.

Most of the non-African scientists who lectured on the course had not previously encountered the conditions in Africa at first hand. They were impressed by the good facilities of the Aaron Klug Centre for Imaging and Analysis, in which the workshop was held. The available resources enabled demonstrations of X-ray crystallography and electron microscope hardware as well as practical experiences in grid preparation and crystal mounting. Participants were able collect data via remote access at a access to the I04 beamline at Diamond - this was a memorable event for those who had previously shipped their own crystals to Diamond and four students were able to determine the structures of their proteins.
An important aspect of the program was the discussion of the new cryo-EM technology that is revolutionizing structural biology. Diamond's electron BioImaging Centre (eBIC) has led the way in making this technology available for academic and industrial use along the same lines as the synchrotron beamlines, with notable success. For most participants, this was the first encounter with high-resolution cryo-EM and they responded enthusiastically to the lectures by Subramaniam Ramaswamy who described the successes achieved with the first Thermo-Fisher Titan Krios installed in India (Ramaswamy et al. 2019), and David Bhella who described the spectacular results obtained at the Scottish Centre for Macromolecular Imaging (SCMI) on the new JEOL cryoARM 300 (Bhella 2019). Both these authors have contributed commentaries on their experiences to this issue.

Also in this edition of BREV, the case for building an African Light Source to support Drug Discovery and Structural Biology is strongly put by Connell et al. (2019). Richard Garratt provides a parallel example of how it was possible to build a synchrotron and user community in Brazil (Garratt 2019). There are important lessons for the Africans here-from small beginnings, the Brazilians have now built a state-of-the-art synchrotron and can solve really difficult problems. Subramaniam Ramaswamy points out that Indian progress in Structural Biology was retarded by the absence of a synchrotron, despite early successes and worldclass researchers (Ramaswamy et al. 2019). A key component 
of any synchrotron are the beamlines, and the important features of the BL44XU beamline at Spring 8, designed for large macromolecules and macromolecular assemblies are described by Yamashita and Nakagawa (2019).

Two particularly interesting case studies are contained in the commentaries by Garman (2019a) and Lawrence (2019) — both commentaries show the rewards of persistence over protracted periods. Lawrence also gave the students the opportunity to rediscover the insulin receptor structure from the crystallographic data.

Underlying all structural work is the preparation of good material. Owens and Gileadi (2019) showed that this could be achieved in reasonable time by testing several recombinant systems in parallel — an approach that was novel to the audience.

Elspeth Garman presented two key tutorials; the essence of each is captured in her two commentaries. In the first, she summarized the key concepts of crystallography in a way that is accessible to modern bioscience students, who do not have a mathematical background (Garman 2019b). In the other, she demonstrated the art of preparing crystals for data collection and all the participants were able to practice mounting crystals under her supervision (Garman 2019c).

Separovic (2019) discussed the use of nuclear magnetic resonance spectroscopy and how it is a valuable complement to the structural biology arsenal. Finally, Eva Pereiro (Pereiro 2019) showed that synchrotrongenerated X-rays were not only useful for visualizing the atomic structures of macromolecules but also could be used to gain valuable insights into the working of cells with phase plate microscopy.

Overall, the commentaries presented in this edition convey the flavor of this landmark workshop that will have a lasting impact on South African Biophysics and Structural Biology.

\section{Compliance with Ethical Standards}

Conflict of Interest Trevor Sewell declares that he has no conflict of interest.
Ethical approval This article does not contain any studies with human participants or animals performed by the author.

\section{References}

Bhella D (2019) Cryo-electron microscopy - an introduction to the technique, and considerations when working to establish a national facility. Biophys Rev 11(4). https://doi.org/10.1007/s12551-01900571-w

Connell SH et al (2019) Towards an African Light Source. Biophys Rev 11(4). https://doi.org/10.1007/s12551-019-00578-3

Garman EF (2019a) Triumph over adversity: structure of arylamine Nacetyltransferase from M. tuberculosis. Biophysical Reviews 11(4). https://doi.org/10.1007/s12551-019-00574-7

Garman EF (2019b) Crystallography 101: diffraction theory and space groups. Biophysical Reviews. 11(4). https://doi.org/10.1007/ s12551-019-00576-5

Garman EF (2019c) Summary of lecture and practical session at Biophysics and Structural Biology at Synchrotrons workshop: cryo-cooling in macromolecular crystallography - why and how? Biophys Rev 11(4). https://doi.org/10.1007/s12551-019-00566-7

Garratt RC (2019) A brief history of protein crystallography in Brazil. Biophys Rev 11(4). https://doi.org/10.1007/s12551-019-00562-x

Lawrence MC (2019) Insulin and its receptor: a grand challenge in structural biology. Biophys Rev 11(4). https://doi.org/10.1007/s12551019-00559-6

Owens RJ, Gileadi O (2019) Streamlining the production of proteins for structural biology. Biophys Rev 11(4). https://doi.org/10.1007/ s12551-019-00565-8

Pereiro E (2019) Correlative cryo soft X-ray tomography of cells. Biophys Rev 11(4). https://doi.org/10.1007/s12551-019-00560-z

Ramaswamy $\mathrm{S}$ et al (2019) The resolution revolution reaches India. Biophys Rev 11(4). https://doi.org/10.1007/s12551-019-00558-7

Separovic F (2019) Biophysics \& Structural Biology at Synchrotrons BSBS 2019 Biological NMR Session. Biophys Rev 11(4). https:// doi.org/10.1007/s12551-019-00521-6

Yamashita E, Nakagawa A (2019) Spring-8 BL44XU, a synchrotron radiation beamline for biological macromolecular assemblies, operated by the Institute for Protein Research, Osaka University. Biophysical Reviews. 11(4). https://doi.org/10.1007/s12551-01900557-8

Publisher's note Springer Nature remains neutral with regard to jurisdictional claims in published maps and institutional affiliations. 